\title{
CONTAGION EFFECT DAN INTEGRASI PASAR MODAL DI KAWASAN ASIA, EROPA DAN AMERIKA
}

\author{
Robiyanto ${ }^{*}$ \\ Aldhi Fajar Hartanto ${ }^{1}$ \\ 1 Fakultas Ekonomika dan Bisnis \\ Universitas Kristen Satya Wacana Salatiga \\ *Corresponding Author, \\ e-mail; robiyanto@staff.uksw.edu
}

\begin{abstract}
Capital market integration is a very interesting topic to study because it is constantly evolving along with the development of time and conditions that occur in the capital markets in the world. This study examines the integration of capital markets and the contagion effect of capital markets in Asia, Europe and America. This study uses monthly closing data of Jakarta Composite Index (JCl) for Indonesia, (KLCl) for Malaysia, PSE Composite Index (PSE) for Philippines, Straight Times Index (STI) for Singapore, SET Index (SET) for Thailand, NIKKEI 225 for Japan, FTSE 100 for UK, DAX 30 for Germany, CAC 40 for France, IBEX 35 for Spain, Dow Jones for USA during period of January 2012 until December 2016. The result of this research is there is no comovement between capital markets of Indonesia, Malaysia, Philippines, Singapore, Thailand, Japan, UK, Germany, France, Italy, Spain and the United States.
\end{abstract}

Keywords: Capital market integration, Contagion effect, Composite Stock Price Index, JEL Classification: G15.

\begin{abstract}
ABSTRAK
Integrasi pasar modal merupakan topik yang masih sangat menarik untuk dikaji karena senantiasa berkembang seiring dengan perkembangan waktu dan kondisi yang terjadi pada pasar modal-pasar modal yang ada di dunia. Penelitian ini mengkaji integrasi pasar modal dan contagion effect dari pasar modal di Asia, Eropa dan Amerika. Penelitian ini menggunakan data penutupan bulanan Indeks Harga Saham Gabungan (IHSG) untuk Indonesia, Kuala Lumpur Composite Index (KLCl) untuk Malaysia, PSE Composite Index (PSE) untuk Filipina, Straight Times Index (STI) untuk Singapura, SET Index (SET) untuk Thailand, NIKKEI 225 untuk Jepang, FTSE 100 untuk Inggris, DAX 30 untuk Jerman, CAC 40 untuk Prancis, IBEX 35 untuk Spanyol, Dow Jones untuk Amerika Serikat selama periode bulan Januari 2012 sampai dengan Desember 2016. Hasil penelitian ini adalah tidak terdapat comovement antara pasar modal Indonesia, Malaysia, Filipina, Singapura, Thailand, Jepang, UK, Jerman, Perancis, Italia, Spanyol, dan Amerika Serikat.
\end{abstract}

Kata kunci: Integrasi pasar modal, Contagion effect, Indeks Harga Saham Gabungan. 
Pada tahun 2007, para pimpinan negara anggota-anggota ASEAN menyetujui adanya cetak biru AEC (ASEAN Economic Community/Masyarakat Ekonomi ASEAN) yang diusung pada akhir tahun 2015. Disamping itu cetak biru AEC direncanakan adanya liberalisasi jasa-jasa keuangan diantara negara anggota ASEAN dengan tujuan untuk mempercepat perkembangan dan integrasi pasar modal. Juga yang tidak kalah pentingnya adalah adanya rencana pengurangan bahkan penghilangan batasan lalu lintas permodalan untuk mencapai arus modal yang lebih bebas di kawasan antar negara anggota ASEAN (Volz 2013; Robiyanto et al. 2016). Hal ini akan mengakibatkan pula bahwa munculnya kejadian ekonomi yang signifikan pada negara lain akan mampu memberikan efek penularan (contagion effect) ke negara-negara sekitarnya, dan hal tersebut juga tidak menutup kemungkinan dapat berimbas ke negara-negara di kawasan ASEAN (Suganda dan Soetrisno 2016).

Baele, et al. (2004) dan Weber (2006) yang mengemukakan bahwa pasar suatu instrumen dan jasa keuangan terintegrasi secara penuh apabila semua pihak potensial yang berpartisipasi dalam pasar dan menghadapi serangkaian aturan ketika melakukan transaksi, kemudian memiliki akses yang setara dan diperlakukan secara sama ketika mereka aktif di pasar. Valle (2000) yang sependapat dengan Baele, et al. (2004) dan Weber (2006), mengatakan bahwa pasar modal dapat mengalami pergerakan yang sama (comovement) karena adanya faktor-faktor ekonomi yang mendasarinya (underlying factors), yang mencerminkan kondisi keuangan di dunia secara umum, dan secara sistematis mempengaruhi semua pasar sehingga berdampak pada comovement pasar modal di berbagai negara.

Jorion dan Schwartz (1986) menyatakan bahwa pasar modal dikatakan terintegrasi secara internasional jika aset-aset dengan resiko yang sama atau identik akan memiliki harga yang sama juga walaupun diperdagangkan di pasar modal yang berbeda. Hal ini berarti resiko dan return berlaku secara internasional dan pergerakan saham di pasar modal tidak hanya dipengaruhi oleh faktor domestik tetapi juga dipengaruhi oleh pergerakan harga saham di pasar-pasar modal dunia (Robiyanto 2017; Muharam 1999). Pendapat yang hampir sama juga dikatakan oleh Bekaert, et al. (2007) yang menyatakan bahwa pada pasar yang memiliki tingkat integrasi dan efek penularan (contagion effect) yang tinggi maka pasar akan bergerak secara bersama-sama dan memiliki tingkat hubungan yang tinggi. Sementara itu kebalikan dari pasar modal yang terintegrasi adalah pasar modal yang tersegmentasi. Suatu pasar modal dapat tersegmentasi apabila memiliki hubungan yang rendah dengan pasar modal yang lain (Bilson 2000).

Banyak penelitian dan kajian dari para ahli bahwa perekonomian suatu negara akan cenderung dipengaruhi oleh perekonomian negara-negara lain. Perekonomian negara yang sudah maju akan cenderung dapat memiliki pengaruh terhadap perekonomian negara yang sedang berkembang sehingga negara kuat atau maju akan cenderung unggul dalam persaingan. Hal yang sama juga terjadi pada pasar saham. Seperti yang diketahui Indeks Harga Saham Gabungan (IHSG) merupakan salah satu variabel ekonomi makro, maka akan sangat mungkin IHSG negara maju cenderung berpengaruh terhadap Indeks Harga Saham Gabungan pada negara berkembang.

Penelitian mengenai integrasi pasar modal beberapa diantaranya dilakukan oleh Mulyadi (2012) meneliti mengenai pengaruh pasar modal di Amerika Serikat dan pasar modal di Jepang terhadap Bursa Efek Indonesia dengan menggunakan data periode Januari 2004 hingga Desember 2008. Hasil penelitian ini ternyata konsisten dengan hasil penelitian yang dilakukan oleh Ibrahim (2006) yang menemukan bahwa pasar modal di Indonesia lebih dipengaruhi oleh pasar modal Amerika Serikat dan pasar modal Jepang, Lebih jauh lagi penelitian Ibrahim (2006) juga menemukan bahwa hubungan pasar modal Amerika Serikat dengan pasar modal Indonesia adalah satu arah 
dalam arti bahwa pasar modal Amerika Serikat mempengaruhi pasar modal Indonesia, hal ini juga didukung pula oleh Triyono dan Robiyanto (2017), sedangkan hubungan pasar modal Jepang dengan pasar modal Indonesia adalah saling mempengaruhi. Menurut Anghelache dan Ciobanu (2012), pasar saham Amerika Serikat dan Jepang memiliki pengaruh yang kuat terhadap pasar saham negara lain yang merupakan objek penelitiannya. Negara-negara tersebut adalah 6 negara dalam kawasan Asia Pasifik, yaitu Hong Kong, Korea, Malaysia, Singapura, Taiwan, dan Thailand.

Berdasarkan uraian di atas maka dalam penelitian ini menganalisis integrasi dan Contagion Effect pasar modal di Asia, Eropa dan Amerika. Indeks Harga Saham Gabungan yang dipergunakan adalah Indeks Harga Saham Gabungan (IHSG) untuk Indonesia, Kuala Lumpur Composite Index (KLCI) untuk Malaysia, PSE Composite Index (PSE) untuk Filipina, Straight Times Index (STI) untuk Singapura, SET Index (SET) untuk Thailand, NIKKEI 225 untuk Jepang, FTSE 100 untuk Inggris, DAX 30 untuk Jerman, CAC 40 untuk Prancis, IBEX 35 untuk Spanyol, Dow Jones untuk Amerika Serikat.

\section{Integrasi Pasar Modal}

Semakin terintegrasinya pasar-pasar modal dalam dunia ditandai oleh makin tingginya korelasi antara return saham antar bursa saham, dimana korelasi yang semakin tinggi disebabkan oleh beberapa hal yaitu bias yang makin menurun dalam pilihan portofolio karena diversifikasi akan makin menghilang manfaatnya (Brooks dan Negro 2002). Brooks dan Negro (2002) juga menyatakan bahwa pasar modal dalam suatu negara dapat mengalami pergerakan yang beriringan (comovement) dengan pasar modal di negara lainnya karena adanya faktor-faktor ekonomi yang mendasarinya (underlying factors), yang mencerminkan kondisi keuangan di dunia secara umum, dan secara sistematis mempengaruhi semua pasar, sebagai contohnya yaitu adanya deregulasi dan liberalisasi pasar, bahkan liberalisasi sistem keuangan. Di sisi lain perkembangan teknologi komunikasi dan sistem perdagangan, inovasi pada produk dan jasa keuangan serta makin meningkatnya aktivitas internasional dari perusahaan-perusahaan multinasional juga makin meningkatkan comovement pasar modal pada berbagai negara.

\section{Contagion Effect}

Kondisi perekonomian suatu negara tidak lagi hanya ditentukan oleh negara tersebut melainkan kondisi perekonomian di negara lain juga menjadi faktor penentu. Contohnya adalah kondisi krisis yang terjadi di dunia pada tahun 2008 lalu di mana menurut penelitian Bank Dunia terutama disebabkan oleh adanya integrasi ekonomi antar negara sehingga menimbulkan contagion effect dari negara lain. Dalam arti luas, contagion adalah transmisi shock antar negara. Apabila suatu negara mengalami shock, maka shock tersebut dapat ter-transfer ke negara lain di sekitarnya (Purnomo dan Rider 2012).

Pasar modal berkembang dengan pesat dari waktu ke waktu terutama di negara berkembang berperan penting dalam perolehan modal atau disebut dengan capital inflow. Capital inflow pada umumnya bukan merupakan berbentuk investasi secara langsung yang sifatnya jangka panjang melainkan jangka pendek. Investor dari dalam dan luar negeri menjadi target dari perolehan modal tersebut sehingga perilaku investor juga dapat menjadi penyebab terjadinya efek domino (contagion) di pasar modal, yakni perilaku investor yang fokus pada peranan likuiditas (Robiyanto, et al. 2017b, 2017a). Apabila suatu negara mengalami masalah geopolitik atau lainnya, maka investor tersebut menangkap indikasi bahwa akan terjadi penurunan performa pada indeks saham negara tersebut, kemudian investor menjual sekuritas di indeks tersebut dan membeli sekuritas di pasar lain 
untuk menghindari kerugian yang besar dan mendapatkan return yang besar di pasar lain. Perilaku investor yang dapat menyebabkan contagion dimana keadaan investor yang tidak mempunyai gambaran lengkap mengenai kondisi dalam setiap negara sehingga didapatkan informasi yang tidak sempurna dan asimetris. Contagion effect semakin besar dengan adanya investasi global dan perdagangan antar negara. Contagion effect yang diteruskan melalui integrasi keuangan juga dapat meningkatkan efek spillover antar negara dikarenakan fluktuasi makro ekonomi (Mulyadi 2012). Data yang dipergunakan dalam penelitian ini adalah penutupan bulanan dari masing-masing indeks harga saham gabungan yaitu Indeks Harga Saham Gabungan (IHSG) untuk Indonesia, Kuala Lumpur Composite Index (KLCI) untuk Malaysia, PSE Composite Index (PSE) untuk Filipina, Straight Times Index (STI) untuk Singapura, SET Index (SET) untuk Thailand, NIKKEI 225 untuk Jepang, FTSE 100 untuk Inggris, DAX 30 untuk Jerman, CAC 40 untuk Prancis, IBEX 35 untuk Spanyol, Dow Jones untuk Amerika, selama periode bulan Januari 2012 sampai dengan Desember 2016. Data diperoleh dari investing.com.

\section{Uji Vector Auto Regression (VAR)}

Vector Auto Regression (VAR) digunakan dalam penelitian ini untuk memproyeksikan sebuah sistem dengan variabel runtut waktu dan untuk menganalisis dampak dinamis dari faktor gangguan yang terdapat dalam sistem variabel yang digunakan. Pada dasarnya analisis VAR sama dengan suatu model persamaan simultan, karena Analisis VAR mempertimbangkan beberapa variabel endogen secara bersama-sama dalam suatu model.

\section{Uji Kausalitas Granger}

Uji kausalitas granger ini dilakukan untuk mengetahui apakah suatu pasar modal mempengaruhi pasar modal yang lain demikian pula sebaliknya. Untuk menentukan signifikansi arah hubungan kausalitas antar variabel menggunakan nilai probabilitas ( $p$ value) yang dihasilkan. Jika probabilitas lebih kecil dari $a=5 \%$ atau 0,05 maka dapat dikatakan terjadi kausalitas yang signifikan.

\section{HASIL DAN PEMBAHASAN}

Uji Augmented Dickey Fuller dan Uji Lag

Sebelum dilakukan analisis VAR dan Granger Causality Test dilakukan uji stasioneritas data yang dilakukan dengan ADF (Augmented Dickey Fuller) untuk level. Jika tidak stasioner maka perlu dilakukan uji derajat integrasi. Uji derajat integrasi dilakukan untuk melihat pada derajat atau diferensi ke berapa data yang diamati akan stasioner. Hasil untuk periode penelititan dapat dilihat pada Tabel 1. Berdasarkan Tabel 1 dapat dilihat bahwa semua variabel memiliki nilai $t$ untuk uji ADF signifikan.

Tabel 1. Augmented Dickey-Fuller Tests Statistic

Periode Januari 2012-Desember 2016

\begin{tabular}{ll}
\hline & $t$ statistic \\
\hline cac & $-8,205686^{*}$ \\
dax & $-7,083704^{*}$ \\
dow & $-8,677265^{*}$ \\
\hline
\end{tabular}


Tabel 1. Lanjutan

\begin{tabular}{ll}
\hline & $t$ statistic \\
\hline ftse & $-10,73807^{*}$ \\
ibex & $-8,234447^{*}$ \\
klci & $-9,25334^{*}$ \\
nikkei & $-6,705869^{*}$ \\
psei & $-6,52661^{*}$ \\
set & $-6,382299^{*}$ \\
sti & $-7,30774^{*}$ \\
ihsg & $-6,855193^{*}$ \\
\hline${ }^{*}$ Signifikan pada 1\%
\end{tabular}

Tabel 2. Uji Lag

\begin{tabular}{ccccccc}
\hline Lag & LogL & LR & FPE & AIC & SC & HQ \\
\hline 0 & 1248,073 & NA & $2.97 e-32^{*}$ & $-44,21689$ & $-43.85522^{*}$ & $-44.07667^{*}$ \\
1 & 1328,413 & $129,1174^{*}$ & $6,30 E-32$ & $-43,51474$ & $-39,53637$ & $-41,9723$ \\
2 & 1404,937 & 95,65518 & $2,03 E-31$ & $-42,67631$ & $-35,08124$ & $-39,7317$ \\
3 & 1515,122 & 98,3801 & $3,90 E-31$ & $-43,04009$ & $-31,82832$ & $-38,6933$ \\
4 & 1688,764 & 93,02248 & $3,88 E-31$ & $-45.67016^{*}$ & $-30,84169$ & $-39,9212$ \\
\hline
\end{tabular}

Uji lag sendiri dilakukan untuk pengujian kausalitas Granger dan mencari hasil yang paling optimum dengan melihat nilai Akaike Information Criteria (AIC). Dari hasil uji lag diatas dilihat pada kolom Akaike Information Criteria (AIC) dan dipilih yang memiliki lag optimum yang bertanda * yang menunjukkan nilai AIC paling rendah.

\section{Analisis Integrasi Pasar Modal Dengan Vector Autoregressive (VAR)}

Dari hasil analisis yang dapat dilihat pada Lampiran 1, diketahui bahwa tidak semua indeks yang mewakili setiap negara memiliki hubungan yang saling berkaitan, hanya beberapa indeks yang mempunyai hubungan seperti KLCl berpengaruh terhadap DAX pada tingkat signifikansi 10\%, $\mathrm{KLCl}$ juga terhadap terhadap DOW dan STI pada tingkat yang sama yaitu 10\%, dan DOW berpengaruh terhadap IBEX pada tingkat $10 \%$ sedangkan berpengaruh terhadap IHSG dan STI pada tingkat $5 \%$. Pada hasil lain indeks FTSE berpengaruh terhadap IBEX dan IHSG pada tingkat signifikan yang sama yaitu 10\%. Untuk IHSG berpengaruh terhadap STI pada level 10\%, dan juga indeks NIKKEI berpengaruh pada indeks IBEX pada tingkat signifikansi $10 \%$.

Ketidakterkaitan pasar modal yang dikaji ini dapat terjadi karena pasar modal cenderung tersegmentasi. Makin berkembangnya pasar modal secara lokal dapat menjadi penyebab hal ini (GIH 2008). Hal ini juga konsisten dengan penelitian Sun dan Tong (2000) yang dilakukan di pasar modal Tiongkok, dan penelitian Hearn dan Piesse (2001) yang dilakukan di pasar modal Afrika Selatan.

\section{Analisis Contagion Effect Dengan Granger Causality Test}

Hasil Granger Causality Test periode 2012-2016 sebagaimana dapat dilihat pada Lampiran 2. menunjukkan bahwa CAC memiliki contagion effect terhadap $\mathrm{KLCl}$, DAX memiliki contagion effect pada KLCI dan PSEI tetapi KLCI dan sedangkan PSEi tidak memiliki contagion effect terhadap DAX. 
Lebih lanjut ditemukan IHSG memiliki contagion effect terhadap DOW tapi DOW tidak memiliki contagion effect tehadap IHSG. Kemudian untuk IBEX memiliki contagion effect terhadap KLCI dan NIKKEI sedangkan KLCI dan NIKKEI tidak memiliki contagion effect.

Hasil lain juga menunjukkan SET memiliki contagion effect terhadap KLCI dan NIKKEI memiliki contagion effect terhadap PSEI, yang terakahir STI memiliki contagion effect terhadap NIKKEI. Dari hasil diatas dapat disimpulkan bahwa indeks masing negara tidak saling berpengaruh, dengan demikian jika terdapat isu-isu pada negara tertentu tidak berpengaruh pada indeks negaranegara lain bahkan negara terdekat. Temuan ini mendukung hasil penelitian Palac-McMiken (1997); (Suganda dan Soetrisno 2016) yang juga menemukan bahwa tidak semua pasar modal dalam satu kawasan memililiki contagion effect.

\section{PENUTUP}

Penelitian ini menyimpulkan bahwa tidak terdapat comovement antara pasar modal Indonesia, Malaysia, Filipina, Singapura, Thailand, Jepang, UK, Jerman, Perancis, Italia, Spanyol, dan Amerika Serikat. Dari sebelas indeks yang diteliti tidak semua memiliki keterkaitan hanya delapan indeks saja yang memiliki pengaruh searah yaitu KLCI, DOW, FTSE, IBEX, NIKKEI, IHSG, STI, dan DAX terhadap indeks yang lain. Namun kedelapan indeks itu tidak memiliki hubungan yang saling mempengaruhi. Kondisi ini dapat terjadi karena fundamental ekonomi negara-negara dengan pasar modal yang diteliti pada saat sangat berbeda dan pasar modal menjadi makin tersegmentasi.

Temuan dalam penelitian ini menunjukkan bahwa investor yang memiliki kapabilitas melakukan portofolio tingkat internasional dapat memperoleh keuntungan diversifikasi pada berbagai pasar modal internasional karena pasar modal tersebut cenderung tersegmentasi. Sementara itu penelitian mendatang dapat melakukan kajian dengan menggunakan alat analisis yang masih jarang digunakan untuk mengkaji integrasi pasar modal seperti OGARCH.

\section{REFERENSI}

Anghelache, G.-V., \& A. N. Ciobanu. (2012). Correlating Stock Exchange Indices Under Both Normal and Financial Crisis Conditions. Theoretical and Applied Economics, 19 (11):75-84.

Baele, L., A. Ferrando, P. Hordahl, E. Krylova, \& C. Monnet. (2004). Measuring Financial Integration in The Euro Area. European Central Bank Occasional Paper Series 14.

Bekaert, G., C. R. Harvey, \& C. Lundblad. (2007). Global Growth Opportunities and Market Integration. Journal of Finance, 62 (3):1081-1137.

Bilson, C. (2000). The Impact of Liberalization and Regionalism upon Capital Markets in Emerging Asian Economics. Asian Financial Crisis: Structural and International Dimensions, International Finance Review 1.

Brooks, R., \& M. D. Negro. (2002). International Stock Returns and Market Integration: A Regional Perspective. Working Paper Series (Federal Reserve Bank of Atlanta), 2:2-27.

$\mathrm{GIH}$. (2008). Challenges of Investing in Emerging Capital Markets: Integration vs. Segmentation. In Second Annual Palestinian Capital Market Forum: Global Investment House

Hearn, B., \& J. Piesse. (2001). Equity Market Integration versus Segmentation in Three Dominant Markets of the Southern African Customs Union: Cointegrating and Causality Process. SSRN Working Paper.

Ibrahim, M. H. (2006). International Linkage of ASEAN Stock Prices: An Analysis of Response Asymmetries. Applied Econometrics and International Development, 3 (3):191-202. 
Jorion, P., \& E. Schwartz. (1986). Integration vs. Segmentation in the Canadian Stock Market. Journal of Finance, 41 (3):603-614.

Muharam, H. (1999). Dampak Pelepasan Batas Kepemilikan Asing Terhadap Terintegrasinya Bursa Efek Jakarta dengan Bursa Efek Internasional (Studi Literatur). Jurnal Bisnis Strategi, 4 (Desember).

Mulyadi, M. S. (2012). Analysis of Volatility Spillover in Indonesia, USA and Japan Capital Market. African Journal of Business Management, 6 (27).

Palac-McMiken, E. D. (1997). An Examination of ASEAN Stock Markets: A Cointegration Approach. ASEAN Economic Bulletin, 13 (3):299-311.

Purnomo, B., \& M. W. Rider. (2012). Domestic and Foreign Shocks and the Indonesian Stock Market: Time Series Evidence. Working Paper.

Robiyanto, R. (2017). The Analysis of Capital Market Integration in ASEAN Region by Using the OGARCH Approach. Jurnal Keuangan dan Perbankan (JKP), 21 (2):169-175.

Robiyanto, R., H. Hersugondo, \& G. S. Chotijah. (2016). ASEAN Economic Community (AEC) and Economic Stability: A Review from Indonesia's Side. International Journal of Economic Research, 13 (2).

Robiyanto, R., S. Wahyudi, \& I. R. D. Pangestuti. (2017a). Testing Commodities as Safe Haven and Hedging Instrument on ASEAN's Five Stock Markets Jurnal Ekonomi Kuantitatif Terapan, 10 (2).

Robiyanto, R., S. Wahyudi, \& I. R. D. Pangestuti. (2017b). The Volatility-Variability Hypotheses Testing and Hedging Effectiveness of Precious Metals for the Indonesian and Malaysian Capital Markets. Gadjah Mada International Journal of Business, 19 (2):167-192.

Suganda, T. R., \& Y. Soetrisno. (2016). Uji Integrasi dan Contagion Effect Pasar Modal Pada Lima Negara ASEAN (Riset Empiris Pasca Terjadinya Krisis Subprime Mortgage dan Krisis Yunani). Jurnal Keuangan dan Perbankan (JKP), 20 (2):252-262.

Sun, Q., \& W. H. S. Tong. (2000). The Effect of Market Segmentation on Stock Prices: The China Syndrome. Journal of Banking \& Finance, 24:1875-1902.

Triyono, D., \& Robiyanto. (2017). The Effect of Foreign Stock Indexes and Indonesia's Macroeconomics Variables Toward Jakarta Composite Stock Price Index (JCl) Advanced Science Letters, 23 (8):7211-7214.

Valle, R. S. (2000). A Cointegration Analysis of Latin American Stock Markets and The U.S. SSRN Working Paper.

Volz, U. (2013). ASEAN Financial Integration in the Light of Recent European Experiences. Journal of Southeast Asian Economics, 30 (2):124-142.

Weber, A. A. (2006). European Financial Integration and (its Implications for) Monetary Policy. In Annual General Meeting 2006 of the Foreign Bankers' Association in the Netherlands. Amsterdam. 


\section{Lampiran 1. Hasil Analisis VAR}

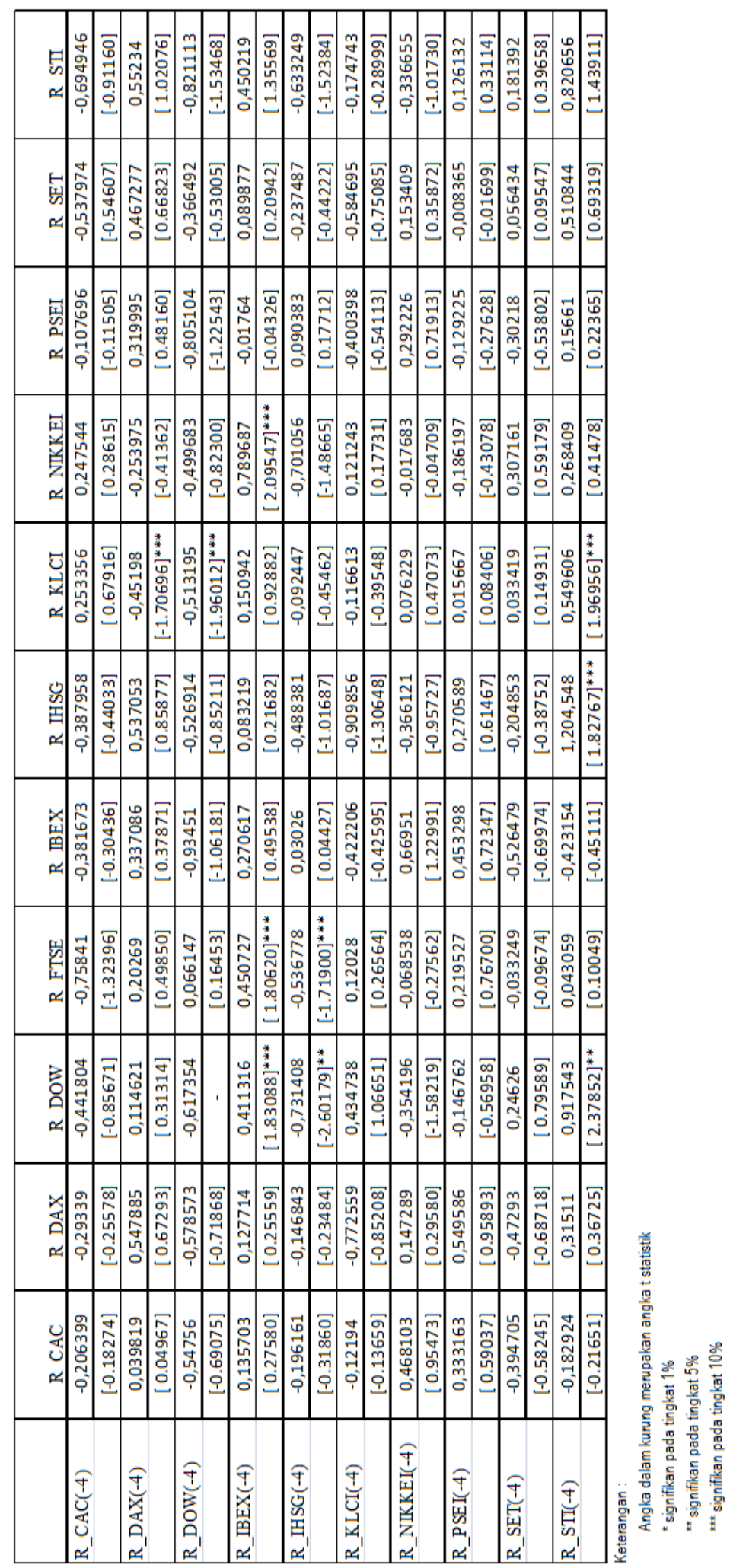


Lampiran 2. Hasil Granger Causality Test

\begin{tabular}{|c|c|c|c|}
\hline Null Hypothesis & Obs & F-Statistic & Prob. \\
\hline R_DAX does not Granger Cause R_CAC & 56 & 195,641 & 0,1167 \\
\hline R_CAC does not Granger Cause R_DAX & & 183,566 & 0,1378 \\
\hline R_DOW does not Granger Cause R_CAC & 56 & 0,21701 & 0,9277 \\
\hline R_CAC does not Granger Cause R_DOW & & 0,26891 & 0,8965 \\
\hline R_FTSE does not Granger Cause R_CAC & 56 & 184,216 & 0,1366 \\
\hline R_CAC does not Granger Cause R_FTSE & & 0,98979 & 0,4224 \\
\hline R_IBEX does not Granger Cause R_CAC & 56 & 0,40961 & 0,8008 \\
\hline R_CAC does not Granger Cause R_IBEX & & 0,48181 & 0,7489 \\
\hline R_IHSG does not Granger Cause R_CAC & 56 & 0,56328 & 0,6904 \\
\hline R_CAC does not Granger Cause R_IHSG & & 135,983 & 0,2622 \\
\hline R_KLCl does not Granger Cause R_CAC & 56 & 0,63328 & 0,6412 \\
\hline R_CAC does not Granger Cause R_KLCl & & 260,633 & 0,0475 \\
\hline R_NIKKEI does not Granger Cause R_CAC & 56 & 132,475 & 0,2746 \\
\hline R_CAC does not Granger Cause R_NIKKEI & & 237,444 & 0,0655 \\
\hline R_PSEl does not Granger Cause R_CAC & 56 & 0,29046 & 0,8827 \\
\hline R_CAC does not Granger Cause R_PSEI & & 243,783 & 0,06 \\
\hline R_SET does not Granger Cause R_CAC & 56 & 0,34138 & 0,8486 \\
\hline R_CAC does not Granger Cause R_SET & & 0,98569 & 0,4245 \\
\hline R_STI does not Granger Cause R_CAC & 56 & 0,64126 & 0,6357 \\
\hline R_CAC does not Granger Cause R_STI & & 148,729 & 0,2212 \\
\hline R_DOW does not Granger Cause R_DAX & 56 & 0,88363 & 0,481 \\
\hline R_DAX does not Granger Cause R_DOW & & 0,87608 & 0,4854 \\
\hline R_FTSE does not Granger Cause R_DAX & 56 & 183,121 & 0,1386 \\
\hline R_DAX does not Granger Cause R_FTSE & & 230,408 & 0,0722 \\
\hline R_IBEX does not Granger Cause R_DAX & 56 & 0,32862 & 0,8573 \\
\hline R_DAX does not Granger Cause R_IBEX & & 119,214 & 0,3266 \\
\hline R_IHSG does not Granger Cause R_DAX & 56 & 0,5537 & 0,6973 \\
\hline R_DAX does not Granger Cause R_IHSG & & 0,93661 & 0,451 \\
\hline R_KLCl does not Granger Cause R_DAX & 56 & 0,07529 & 0,9894 \\
\hline R_DAX does not Granger Cause R_KLCl & & 313,102 & 0,0231 \\
\hline R_NIKKEI does not Granger Cause R_DAX & 56 & 0,31807 & 0,8645 \\
\hline R_DAX does not Granger Cause R_NIKKEI & & 167,622 & 0,1713 \\
\hline R_PSEl does not Granger Cause R_DAX & 56 & 0,95145 & 0,4429 \\
\hline R_DAX does not Granger Cause R_PSEI & & 265,966 & 0,0441 \\
\hline R_SET does not Granger Cause R_DAX & 56 & 113,686 & 0,3508 \\
\hline R_DAX does not Granger Cause R_SET & & 0,93519 & 0,4518 \\
\hline R_STI does not Granger Cause R_DAX & 56 & 0,30169 & 0,8754 \\
\hline R_DAX does not Granger Cause R_STI & & 212,379 & 0,0926 \\
\hline R_FTSE does not Granger Cause R_DOW & 56 & 0,52557 & 0,7174 \\
\hline R_DOW does not Granger Cause R_FTSE & & 0,60258 & 0,6627 \\
\hline R_IBEX does not Granger Cause R_DOW & 56 & 0,26773 & 0,8972 \\
\hline R_DOW does not Granger Cause R_IBEX & & 0,30288 & 0,8746 \\
\hline R_IHSG does not Granger Cause R_DOW & 56 & 282,048 & 0,0354 \\
\hline R_DOW does not Granger Cause R_IHSG & & 0,42255 & 0,7916 \\
\hline
\end{tabular}

